\title{
Climate Change Perception in Lebanon: An Exploratory Study
}

\author{
Akil Hussein ${ }^{1}$, Trabulsi Hussein ${ }^{1} \&$ Grace Moussaid $^{2}$ \\ ${ }^{1}$ Faculty of Economics and Business Administration, Lebanese University, Nabatieh, Lebanon \\ ${ }^{2}$ Faculty of Economics and Business Administration, Université Occidentale de l'Ouest, Brest, France \\ Correspondence: Hussein Akil, Faculty of Economics and Business Administration, Lebanese University, \\ Nabatieh, Lebanon. E-mail: hussein.akil@hotmail.fr
}

$\begin{aligned} & \text { Received: February 10,2019 Accepted: September 9, } 2019 \quad \text { Online Published: September 29, } 2019 \\ & \text { doi:10.5539/ijms.v11n4p53 }\end{aligned}$ URL: https://doi.org/10.5539/ijms.v11n4p53

\begin{abstract}
This paper is intended to explore the Climate Change (CC) perception in Lebanon. An exploratory study based on individual interviews is conducted. The results of in this study reveal that only a small percentage of citizens have high level of CC perception and intentions to reducing carbon lifestyle. The results demonstrate that the CC is a marketing-communication problem that generates individual barriers to decarbonisation. These findings imply new marketing-communication recommendations.
\end{abstract}

Keywords: climate change, communication, culture, marketing, perception

\section{Introduction}

In the 21st century, climatic disturbances have both multiplied and amplified. Tsunamis, tornadoes, cyclones, floods, heat waves, melting glaciers, ocean acidification, desertification, droughts and other cataclysms are at the forefront of the international media scene. Societies around the world are now aware of the consequences of CC, which are abruptly and irreversibly embedded in our history (Denhez \& Petit, 2005; Solomon et al., 2008).

The evidence was reported as early as 1985 by the extraction of Antarctic ice cores testifying to more than 160000 years of climatic variations. From the ice ages to the warmest periods of the planet, the temperature curves have always followed those of the concentration of carbon dioxide $\left(\mathrm{CO}_{2}\right)$. But this has steadily increased since the Industrial Revolution of the mid-19th century and the $\mathrm{CO}_{2}$ content of the atmosphere has never been higher (Descamps, 2015).

The news and the importance of the subject are not only related to the many scientific findings, more and more salient about the reality of the CC, but also to the current or expected consequences of the CC (IPCC, 2007, 2013). This translates into millions of scientific publications, media articles, national and international conferences, implementation of local and global strategies and policies. The international community has seized upon this problematic, which potentially calls into question the survival of the human species. The United Nations established in 1988 an Intergovernmental Panel on Climate Change (IPCC). Over the decades, their findings have removed controversies about the anthropogenic origin of CC: human activity is the cause of these climatic disturbances. This is called an "anthropogenic CC" (Álvarez-Iglesias et al., 2012; Crutzen, 2000).

It is therefore the current lifestyles and consumption - to each one and everyone - that are today critically questioned (Coutrot et al., 2011; Frémeaux et al., 2014; Wells et al., 2010). However, while the imperative of reducing greenhouse gas (GHG) emissions is officially shared by all states, poles of political, industrial and financial resistance remain here.

In the face of urgency, various actors (e.g., non-governmental organizations (NGOs), governments, environmental activists, etc.) have been mobilized and are involved in the fight against CC. Yet, despite the awareness, the strategies, and the actions taken, the state of affairs continues to worsen without the States managing to agree on a more voluntary path. The struggle against the $\mathrm{CC}$ continues to face many obstacles and barriers, at the macro- (states, e.g., economic growth), meso- (companies, e.g., industrial lobbies) and micro-levels (individual, e.g., interest staff).

In the macro, meso-economic and political context that we have just described, how do the Lebanese citizens position themselves? Alas, international institutional apathy responds to a relative behavioral apathy of the citizen. The citizens are lost by political controversies and battles of lobbies that overwhelm them, crushed by 
vital and deeply anxious social issues (Doherty \& Clayton, 2011; Feinberg \& Willer, 2011; Leiserowitz, 2006; Mauger-Parat \& Peliz, 2013; Moser \& Dilling, 2007, 2011).

Namely, in this paper, we are interested in the micro-individual level rather than the macro level.

We seek to understand how the Lebanese community perceives CC. Why do citizens have very low engagement in carbon sobriety? What are the barriers to changing consumer behavior? How to overcome these effectively?

The theoretical lack on these questions in Management Sciences generally, and Marketing particularly, has challenged us and aroused an interest to develop this line of research. This research study also focuses: 1) to identify the ecological literacy of the Lebanese citizens and the causes of apathy related to prevention communication campaigns on CC that aim to change citizen behavior; 2) to identify the causes of behavioral inaction in carbon sobriety from a management and marketing perspective; and 3) to contribute scientifically to the reduction of GHG emissions as researchers by proposing useful ways to the construction of new and more efficient marketing-communication strategies.

\section{Theoretical Context}

The term "climate" is derived from the Latin word "climatis", which itself comes from the Greek word "klima" meaning "inclination". A climate, therefore, means the inclination of the Earth compared to the Sun. As this etymology suggests, climate is a scientific concept that physically accounts for seasons and climatic zones distributed at different spatio-temporal scales on the surface of the globe according to the inclination of the Earth towards the pole (Scarwell \& Roussel, 2010).

Aristotle (384-322 BC) defines climatology in its geography (Staszak, 1992). The physicist is the first to cut the globe into geo-climatic zones, while ignoring the mean and spatial differentiations. In short, what we call "zone" depends only on the degree of inclination of the Sun, which makes it possible, through mathematic calculations, to cut the globe into climates (Staszak, 1992). Five original zones (i.e., climates) were thus delineated by Aristotle to define the concept of climate and to identify the cultivation zones of the terrestrial globe. The first area is a torrid zone, central, at the equator, that the physicist considers uninhabitable because of the high temperature. Then two peripheral areas, near the poles, that are also considered uninhabitable (i.e., Arctic and Antarctic) this time because of the low temperatures. And lastly, two temperate intermediate zones, that are considered as the only ones with a climate in adequacy with the durability of life (i.e., northern and southern).

Besides, the definition of climate has changed since the Aristotelian vision of the world. The mathematical approach now dominates the purely geographical approach. Climatology, science or the study of climate is a necessarily recent discipline, since it supposes the existence of measures to calculate averages (Scarwell \& Roussel, 2010). The notion of mean, so essential to the characterization of a climate (metrological variability) during a given period, is totally foreign to the Aristotelian approach (Staszak, 1992).

The term "climate" is today inseparable from those of "change", "imbalance" or "warming". These new semantics have also transgressed the old definitions of CC (Scarwell \& Roussel, 2010). Climate change, alas, results in a lasting change in the statistical parameters of the global climate of the Earth or its various regional climates at an unequivocal pace. Its determination is thus established via the statistical measurements of these local atmospheric data (mainly by temperature, atmospheric pressure, sunshine, humidity, and wind speed) over several periods (from a decade to a million years). Climate variability can sometimes be attributed to intrinsic processes of the Earth, and other times, to external influences.

In the early studies conducted by the Intergovernmental Panel on Climate Change (IPCC), the term "climate change" was in fact referred to any change over time, whether due to natural variability or human activities. Yet over the years, the IPCC has gradually redesigned and refined the outlines of this notion. As per the latest scientific evidence, it is now considered extremely likely that the climate change planet Earth is undergoing due to the increase in GHG concentrations is mainly attributable to human activities. For example, in the United Nations Framework Convention on Climate Change (UNFCCC, New York, 1992), the term "CC" refers to changes solely due to human activities, poor human-nature interaction, and "climatic variability" means climate change strictly of natural origin.

For a long time now, the scientific community has been drawing the attention to climate change. The Swedish chemist Svante Arrhenius (1859-1927) realized very early the consequences of human activities on the climate. He was the first author to affirm this phenomenon and its origin (i.e., the anthropogenic accentuation of the greenhouse effect), claiming in 1896 in a scientific publication, that the combustion of oil and coal generated by human activities could result in a doubling of the amount of atmospheric $\mathrm{CO}_{2}$, thus causing an upward change in the Earth's temperature. 
Since then, research has indeed progressed, and the speeches and affirmations have multiplied. Callendar (1938) points out that the atmospheric concentrations of $\mathrm{CO}_{2}$ are increasing and can lead to global warming. Denhez and Petit (2005) suggest that increasing concentrations of greenhouse gases in the Earth tend to break the balance. According to these authors, this is an additional accumulation of $\mathrm{CO}_{2}$ into the atmosphere that is not completely eliminated and on the other hand, the absorption rate is not great enough. As such, only half of these gases would be recycled by nature, while the other half would remain in the atmosphere and increase the GHG effect. Similarly, Ki-Moon (2008) noted that: "Our world is trapped in a dangerous habit of $\mathrm{CO}_{2}$ dependence".

As per these various observations, the research team aims to comprehend how the Lebanese citizens perceive CC and how they react against the concept of CC. Importantly, the team aims to evaluate how we can, in the fields of management and marketing, explain the failure of climate communication registers, the social apathy of the citizen and the increase of GHGs in the atmosphere. These questions guide this research objective and will provide many contributions at once, both theoretical and managerial.

In the next section, the methodological context of the research are presented, aiming to extend and deepen the scientific understanding of Lebanese citizens' behaviors in terms of CC perception and fight against CC.

\section{Methodological Context}

The research team adopted a qualitative approach through semi-structured interviews, based on a guide elaborate identifying the different information needs as briefly described below. The interviews were conducted individually, face-to-face, with Lebanese citizens.

This method of data collection is the most recommended when a research team aims to address specific and well-targeted topics such as this qualitative research project (Evrard, Pras, \& Roux, 2009). This method allows obtaining rich, deep, diverse, and above all, quality content. It is also used to elicit human "subjectivity" over a given problem. More precisely, this method serves to understand the diversity of viewpoints, comprehension, opinions, values, experiences, beliefs and attitudes on a certain topic. Semi-structured interviews are, in fact, being increasingly adopted in the literature to elicit discourses surrounding the issue of CC (Niemeyer et al., 2005; O’Neill \& Nicholson-Cole, 2009; Hobson \& Niemeyer, 2011).

The interviews have been recorded. The recorded interviews were then fully transcribed. Each interview lasted approximately 30 to 40 minutes. All these interviews constituted a corpus of 118 pages after transcription.

The interview guide utilized in this research project was developed in advance. It consists of questions that gather the necessary information and respond to the research questions understudy. The questions relate, on the one hand, to mental phenomena-opinions, attitudes and intentions - and, on the other hand, to behaviors (Evrard, Pras, \& Roux, 2009).

The interview guide is composed of several themes and is followed by a short questionnaire on the citizen culture, as well as its relationship with environmental and materialistic consumption, in order to determine the dominant culture in the Lebanese society and the mechanism for extending self-esteem. The questions were hence developed based on thorough literature review on this subject (Alexander, 2009; Boykoff, 2007; Feinberg \& Willer, 2011; Hamilton, 2010; Kerr, 2007; O’Neill \& Nicholson-Cole, 2009).

As it is recommended to include a total of 15 to 30 interviews in such qualitative study samples (Evrard, Pras, \& Roux, 2009), the team in this research project conducted a total of 19 interviews with Lebanese citizens, who were volunteer participants. This number of people was deemed sufficient after having noted the acquisition of the principle of theoretical saturation (Glaser, 2009). This principle stipulates that any new maintenance, beyond those already carried out, does not bring any new element. These participants were all residing in Beirut region in Lebanon, of different ages (between 22 and 54 years of age), gender (50\% of interviewees were women) and education levels ( $50 \%$ students).

As for analysis, content analysis was adopted. According to Bardin (1977 and 2007), content analysis is "a set of techniques of communication analysis aimed, through systematic and objective procedures of descriptions of the content of messages, to obtain indicators allowing the inference of knowledge of the production conditions of these messages". This method allows the analysis the content of the speeches of the semi-structured interviews carried out.

As such, after the transicption process, the research team cut the texts horizontally and then vertically into basic analysis units. The cut-out texts were then regrouped into homogeneous and exhaustive categories around each theme.

Afterwards, in each theme, there was an identification and quantification of vocabularies, terms, key words and 
meaningful sentences that would help the research team in the analysis of the information. Similarly, participants' verbatim statements expressing strong ideas were selected and highlighted to serve as evidence and give meaningful context when presenting the results of the analysis.

\section{Analysis and Results}

This part is dedicated to the presentation and analysis of the results of the research study conducted among Lebanese citizens.

The content analysis coding manual of interview revealed several verbatim and themes that emerged. All verbatim confirm misunderstanding of $\mathrm{CC}$ and the low levels of $\mathrm{CC}$ perception and ecological literacy. The verbatim also clearly indicate that the inaction to reduce $\mathrm{CC}$ and decarbonization intentions depends on several reasons which are aggregated into personal, psychological, cultural, and political. The most relevant and significant verbatim and concepts are depicted in table 1 below.

Table 1 . The different themes of analysis and verbatim transcption of interviews

\begin{tabular}{|c|c|}
\hline Themes & Verbatim examples \\
\hline \multirow[t]{4}{*}{ Perceptual distance } & We are not really in a country where we can clearly see the CC. (I8) \\
\hline & If you go to other countries, to the United States or China for example, you can see the difference. (I2) \\
\hline & We don't know in which place it is, maybe in Africa, where they are exposed to this kind of phenomena. (I3) \\
\hline & I do not feel too concerned because it does not happen to me and I don't see it with my own eyes. (I9) \\
\hline \multirow{4}{*}{$\begin{array}{l}\text { Disempowerment and } \\
\text { irresponsibility }\end{array}$} & It is not me who caused the CC. (I1) \\
\hline & These are the rich people who contribute to the CC. (I12) \\
\hline & These are the Americans and the gulf countries. (I19) \\
\hline & In Lebanon, we cannot change because we are not many. (I10) \\
\hline \multirow{4}{*}{$\begin{array}{l}\text { Ecological literacy and } \\
\text { ignorance }\end{array}$} & What is the relationship between floods and climate change? (I4) \\
\hline & I do not think that if we do the recycling and sorting, we can change the situation. (I14) \\
\hline & Climate change, we are for nothing and we cannot change. (I11) \\
\hline & Climate change, I don't believe it, it's not a real story... it's an American story. (I7) \\
\hline \multirow{4}{*}{$\begin{array}{l}\text { Confusion between } \\
\text { scientific concepts }\end{array}$} & I do not know that climate change is pollution. (I16) \\
\hline & I think it is a question of weather and naturel variation of temperature. (I5) \\
\hline & It is the problem of the ozone. (I9) \\
\hline & It's a war and economic phenomenon. (I13) \\
\hline \multirow[t]{4}{*}{ Political inconsistency } & Politicians are the cause of climate change. (I17) \\
\hline & Politicians just want to raise money and haven’t paid to reduce climate change. (I13) \\
\hline & Politicians do not care about people even if they die, so for the CC it's even worse. (I18) \\
\hline & If we want to reduce climate change, we must not count on politicians. (I2) \\
\hline \multirow[t]{3}{*}{ Materialistic culture } & It's not because of climate change that I'm not going to use my car or the plane for traveling. (17) \\
\hline & We cannot go back after what we currently have in terms of comfort. (I9) \\
\hline & We cannot continue without technology and modern life, it is impossible today. (I9) \\
\hline \multirow[t]{4}{*}{ Concern and preoccupation } & The climate change is not a priority for me. (I15) \\
\hline & We have not eaten, so we cannot think about sorting. (I15) \\
\hline & Other issues concern me more than $\mathrm{CC}$, poverty and education for example. (I17) \\
\hline & It will first be necessary to make economic development and thus think of sustainable development. (I6) \\
\hline
\end{tabular}

\section{Discussion and Conclusion}

This research study explored how Lebanese people perceive $\mathrm{CC}$ and react to this environmental phenomenon. As per the results of the interviews conducted, the research team can conclude that $\mathrm{CC}$ may not be an important topic to Lebanese people as it is not a priority concern for them.

The current Marketing-communication plan may not be effective enough to increase the CC perception and modify the behaviours of the citizens and action to decarbonisation. The verbatim of this research study demonstrate that an educational and informative strategy of marketing may be required to increase the perception of $\mathrm{CC}$ and individual decarbonization project. $\mathrm{CC}$ is not just a political pro-environmental problem; but it is also a marketing communication problem. A marketing-communication program that explains the climatic phenomenon, its causes, consequences and solutions to reduce its effects, may be deemed necessary.

The results obtained in this study are compatible to those obtained in previous studies that show that $\mathrm{CC}$ is an education, culture and marketing problem (Fritsche et al., 2010; Schultz et al., 2004; author et al., 2017). As such, it may be critical at this stage to find proper interventions and means in order increase the $\mathrm{CC}$ knowledge and the 
environmental culture in Lebanon.

More importantly, it is crucial to call out for all stakeholders (state, governmental institutions, companies, local and international NGOs, etc.) to invest in researching this topic and mainstreaming its value and relevance to our every-day life, especially that it represents the topic of century and society. Their coordinated contribution will support the Lebanese citizens to adopt a eco-friendlier culture and consequently, pro-climate actions.

The decision of eco-friendly consumption is related to the source of culture and self-worth (Brook, 2005) as well as to the values and norm systems (Fritsche et al., 2010) of the consumer. It is, therefore, essential to showcase pro-environmental cultures and people's connection with nature (Schultz, 2004), as well as green skills in this society to make the transition towards a sustainable society. It is also important to increase the carbon labelling of products and services, which may allow the consumer to become more familiar with this environmental consumption system. Increasing the use of ecological nudges also hinders the worsening of CC by steering the consumer towards green acts automatically.

This work enriches the corpus of marketing literature through the concepts imported from marketing and climatology to explain the CC perception. This is the first paper that investigates the CC perception in Lebanon as social marketing issue. The objective was to increase the involvement of Lebanese people on CC issue. This paper aimed at obtaining the scientific contributions discussed in other disciplines and absent in the field of Marketing regarding the causes of consumer inaction against messages related to anti-CC appeals, unlike the studies on tobacco, road safety, alcohol and drugs abuse which are widely explored. The aim behind this project was to contribute scientifically in reducing GHG by guiding and assisting stakeholders and organizations to prioritize this subject in order to create and develop effective communication strategies for low-carbon consumption. The main challenge remains, however, on the engaging and proper means to involve consumers in the ecological transition behaviour via innovative communications carried out by stakeholders in the various fields concerned.

Some limitations have emerged in our study that reduce the internal and external validity of our research. As example of these limitations concerns the population studied. We interviewed participants living in Beirut (capital of Lebanon) and the choice (homogeneity of sample) of this population impacts their statistical and geographic representativeness. To reduce the "selection bias" concerning this sample, we only chose people from this city.

Finally, it would be important for future research projects to replicate this research project on a sample that is more representative of the Lebanese population and additionally in other countries in order to compare the similarities and difference in perception amongst different cultures. A study of associations between CC visuals like that of a collage would also be relevant for future research. Furthermore, it will be essential to assess the participants' perception of CC, memorization, and hence actions.

\section{References}

Álvarez-Iglesias, P., Rubio, B., \& Millos, J. (2012). Isotopic identification of natural vs. anthropogenic lead sources in marine sediments from the inner Ría de Vigo (NW Spain). Science of the Total Environment, 437(15), 22-35. https://doi.org/10.1016/j.scitotenv.2012.07.063

Barkemeye, R., Dessai, S., Monge-Sanz, B., Renzi, B. G., \& Napolitano, G. (2016). Linguistic analysis of IPCC summaries for policymakers and associated coverage. Nature Climate Change, 6, 311-316. https://doi.org/10.1038/nclimate2824

Boykoff, M. T. (2007). Flogging a dead norm? Newspaper coverage of anthropogenic climate change in the United States and United Kingdom from 2003 to 2006. Area, 39(4), 470-481. https://doi.org/10.1111/j.1475-4762.2007.00769.x

Callendar, G. S. (1938). The artificial production of carbon dioxide and its influence on temperature. Quarterly Journal of the Royal Meteorological Society, 64(275), 223-240. https://doi.org/10.1002/qj.49706427503

Confalonierie, U., Menne, B., Akthar, R., Ebi, K. L., Hauengue, M., Kovats, R. S., Revich, B., \& Woodward, A. (2007). Human health. Climate Change 2007: Impacts, Adaptation and Vulnerability. Contribution of Working Group II to the Fourth Assessment Report of the IPCC, Parry ML. Canziana OF. Palutikof JP. van der.

Coutrot, T., Flacher, D., \& Méda, D. (2011). Pour en finir avec ce vieux monde: les chemins de la transition. Paris: Utopia.

Crutzen, P., \& Stoermer, E. F. (2000). The Anthropocene, Global Change. IGBP Newsletter, 41, 17-18. 
Denhez, F., \& Petit, M. (2005). Atlas de la menace climatique: le réchauffement de l'atmosphère: enjeu numéro un de notre siècle. Paris: éd. Atlas/Monde.

Descamps, P. (2015). De la science à la politique, Comment éviter le chaos climatique? Le Monde diplomatique, November, 13.

Doherty, T. J., \& Clayton, S. (2011). The psychological impacts of global climate change. American Psychological Association, 66(4), 265-276. https://doi.org/10.1037/a0023141

Evrard, Y., Pras, B., \& Roux, E. (2003). Market études et recherche en marketing. Dunod.

Feinberg, M., \& Willer, R. (2011). Apocalypse soon? Dire messages reduce belief in global warming by contradicting just-world beliefs. Psychological Science, 22(1), 34-38. https://doi.org/10.1177/0956797610391911

Frémeaux, P., Kalinowski, W., \& Lalucq, A. (2014). Transition écologique, mode d'emploi. Paris: Les Petits Matins.

Fritsche, I., Jonas, E., Kayser, D., \& Koranyi, N. (2010). Existential threat and compliance with pro-environmental norms. Journal of Environmental Psychology, 30(1), 67-79. https://doi.org/10.1016/j.jenvp.2009.08.007

Glaser, B., \& Anselm, L. S. (1967). The discovery of grounded theory: strategies for qualitative research. Chicago: Aldine.

Hamilton, C. (2010). Requiem for a species: why we resist the truth about climate change. London: Earthscan.

IPCC. (2007). Climate change 2007: climate change impacts, adaptation and vulnerability (pp. 7-22). WGII Summary for Policymakers. Cambridge, UK: Cambridge University Press.

Kerr, R. A. (2007). Pushing the scary side of global warming. Science, 316(5830), 1412-1415. https://doi.org/10.1126/science.316.5830.1412

Leiserowitz, A. (2006). Climate change risk perception and policy preferences: the role of effect, imagery and values. Climatic Change, 77(1-2), 45-72. https://doi.org/10.1007/s10584-006-9059-9

Mauger-Parat, M., \& Peliz, A. (2013). Controverse, polémique, expertise: trois notions pour aborder le débat sur le changement climatique en France. VertigO - la revue électronique en sciences de l'environnement, 13(2). https://doi.org/10.4000/vertigo.14297

Moser, S. C., \& Dilling, L. (2007). Creating a climate for change: Communicating climate change and facilitating social change. Cambridge: Cambridge University Press. https://doi.org/10.1017/CBO9780511535871

Moser, S. C., \& Dilling, L. (2011). Communicating climate change: Closing the science-action gap. In J. S. Dryzek, R. B. Norgaard \& D. Schlosberg (Eds.), The Oxford handbook of climate change and society (pp. 161-174). Oxford: Oxford University Press. https://doi.org/10.1093/oxfordhb/9780199566600.003.0011

Niemeyer, S., Petts, J., \& Hobson, K. (2005). Rapid climate change and society: assessing responses and thresholds. Risk Analysis: An International Journal, 25(6), 1443-1456. https://doi.org/10.1111/j.1539-6924.2005.00691.x

O'Neill, S. J., \& Nicholson-Cole, S. (2009). Fear won't do it promoting, positive engagement with climate change through visual and iconic representations. Science Communication, 30(3), 355-379. https://doi.org/10.1177/1075547008329201

Scarwell, H. J., \& Roussel, I. (2010). Le changement climatique: quand le climat nous pousse à changer d'ère. Presses Univ. Septentrion.

Schultz, W., Shriver, C., Tabanico, J., \& Khazian, A. (2004). Implicit connections with nature. Journal of Environmental Psychology, 24(1), 31-42. https://doi.org/10.1016/S0272-4944(03)00022-7

Solomon, S., Gian-Kasper, P., Reto, K., \& Friedlingstein, P. (2008). Irreversible climate change due to carbon dioxide emissions. National Academy of Sciences, 106(6), 1704-1709. https://doi.org/10.1073/pnas.0812721106

Staszak, J. F. (1992). À la recherche du climat dans les météorologiques et dans l'œuvre d'Aristote. Géographie et Cultures, 1, 105-118. https://doi.org/10.4000/gc.2553

Wells, V. K., Ponting, C. A., \& Peattie, K. (2011). Behavior and climate change: consumer perceptions of 
responsibility. Journal of Marketing $\quad$ Management, $\quad$ 27(7-8), https://doi.org/10.1080/0267257X.2010.500136

\section{Copyrights}

Copyright for this article is retained by the author, with first publication rights granted to the journal.

This is an open-access article distributed under the terms and conditions of the Creative Commons Attribution license (http://creativecommons.org/licenses/by/4.0/). 